\title{
Soil Structural Behavior as a Function of the Amount of Coverage of Maize and Oat Straw on Oxisol on Subtropical Region
}

\author{
Joaquim O. Pereira ${ }^{1}$, Valter B. Dantas ${ }^{2}$, Suedemio de L. Silva ${ }^{1}$, Rafael de O. Batista ${ }^{1}$, Roberto V. Pordeus ${ }^{1}$, \\ Marineide J. Diniz ${ }^{1}$, Francisco A. de Oliveira ${ }^{3} \&$ Paulo C. F. Linhares ${ }^{3}$ \\ ${ }^{1}$ Departamento de Engenharias e Ciencias Ambientais, Universidade Federal Rural do Semi Árido, Mossoró, \\ Brazil \\ ${ }^{2}$ Centro de Ciencias Exatas, Universidade Federal Rural do Semi Árido, Mossoró, RN, Brazil \\ ${ }^{3}$ Centro de Ciências Agrárias, Universidade Federal Rural do Semi Árido, Mossoró, RN, Brazil \\ Correspondence: Joaquim Odilon Pereira, Departamento de Engenharia e Ciências Ambientais, Universidade \\ Federal Rural do Semi Árido, Rua Francisco Mota, 572, CEP 59625, 900 Mossoró, RN, Brazil. Tel: \\ 55-843-317-8200. E-mail: jodilon@ufersa.edu.br
}

Received: February 19, $2019 \quad$ Accepted: April 5, $2019 \quad$ Online Published: May 31, 2019

doi:10.5539/jas.v11n 7 p246

URL: https://doi.org/10.5539/jas.v11n7p246

\begin{abstract}
It is undeniable which soil management systems with intensive use of machines and with little formation of organic matter result in the deterioration of the soil structure. The relation among the values of organic matter in the soil profile as function of the quantity of residue left on the soil surface during the harvest has been little documented. This evaluation will be very important to provide and to apply the best optimization model of the soil management system. The objective of this work was to value the contribution of the mulch cover of maize and oat straw, applied in the soil surface at different quantities and of the soil textural porosity at the change of the soil structural porosity. The experiment was carried out from August to November 2005 on a Oxisol, with clay texture, located at the Experiment Farm of Agricultural Engineering from the UNIOESTE, Cascavel, Paraná, Brazil $\left(24^{\circ} 54^{\prime} \mathrm{S} ; 53^{\circ} 31^{\prime} \mathrm{W}\right)$. The average soil texture in top $20 \mathrm{~cm}$ was 126,195 and $679 \mathrm{~g} \mathrm{~kg}^{-1}$ of sand, silt and clay respectively. Aggregates sizes distribution, soil bulk density, particles density and textural density and soil organic matter were determined at the laboratory for evaluation of the soil structural parameters. For all conditions: application rates, and distribution in the layers of soil depth, the cover with oat straw produced more organic matter and presented a positive effect faster on the soil structural voids ratio than the coverage with maize straw.
\end{abstract}

Keywords: maize straw, mulch, soil cover residue, soil textural density, structural void ratio

\section{Introduction}

The excessive use of heavy machines on the tillage system is known worldwide like an important element that produces soil compaction that is a threat to fertility and to sustainability of the agricultural production systems. It is undeniable which soil management systems with intensive use of machines and with little formation of organic matter result in the deterioration of the soil structure.

The soil microbiota - great number of small lively beings as ants, beetles, larvae, slugs, snails, worms, funguses and seaweeds - acts in the formation and in the aggregates stability and in the ciclagem of nutritious ones, being an indicator of the quality of the ground, feeding on organic matter originating from the remains of cultures or remains of animals.

Crop production practices such as tillage residue management, crop rotation, and conservation tillage system influence organic matter levels in soil. The use of conservationist practices of soil management has been receiving great emphasis, basically, in what it refers to the maintenance and to the improvement of the physical, chemical and biological properties of the soil cultivated and its implications in the yield of the cultures (Brussaard \& Faassen, 1994, Sharma et al., 2011; Pereira et al., 2018). The maintenance of the organic matter content, in values higher, in the soil superficial layer, principally, in the conservationist systems results from the accumulation of vegetable residues (mulch). The presence of residues in the soil surface protects the ground against the erosion and increases its capacity of support (McGregor et al., 1990; Boiffin \& Monnier, 1994), 
absorbs part of the energy of compaction produced by the traffic of machines and animals (Aragón et al., 2000) and changes its physics conditions (temperature, water content and oxygen) necessary to germination (Richard \& Boiffin, 1990; Shinners et al., 1994). According to Barral et al. (1998), among others elements, such as aluminium or iron oxides, colloidal silica or calcium carbonate, the organica matter has role important as cimenting particles to form stable aggregates whoch spatial arrangement largely determines the complementary porous volume of the soil, and thus influences mass- and energy-transfer properties, while the interparticular unions condition the soil strength. In this sense, several authors (Guérif, 1979; Gupta et al., 1987; Zhang et al., 1997; Annooussamy, 1999; Barzegar et al., 2000) researched the influence of the incorporation of cultures residues, such as wheat, corn and sugar-cane in the soil, on the reduction of the soil compaction. However, the relation among the values of organic matter in the soil profile as function of the quantity of residue left on the soil surface during the harvest has been little documented. This evaluation will be very important to provide and to apply the best optimization model of the soil management system. The intensive mechanization and its use in unsuitable conditions, has been altering the soil physical characteristics in variable degrees. The principal alterations are shown up by modifications in the values of soil bulk density, total porosity, distribution of the diameter of the pores and structural porosity, aggregation and organic matter (Eynard et al., 2006).

The literature has been showing also the importance of the distribution of size of pores by characterization of the evolution of the soil (Richard et al., 2001), capacity of retention of water (Fox et al., 2004) as well as they are used to describe effects of the management of the soil agricultural (Lipiec \& Hatano, 2003) and widely influenced by the soil aggregates (Lipiec et al., 2007). Tariq and Durnford (1993) presented shrinkage data as a curve of void ratio, $e$ (volume of voids per unit volume of solids), against the water ratio, $\partial$ (volume of water by volume of solid). Different stages of shrinkage can be identified and the extent of each depends inter alia upon whether the soil is poorly or well structured to saturation. Generally, there are four distinct shrinkage ranges that can be distinguished in a typical shrinkage characteristic curve and all four ranges are not always present. These ranges are generally referred to as (a) structural, (b) normal, (c) residual and, (d) zero-shrinkage. In structural range, large water-filled pores may be emptied without the accompanying equal soil volume change. In the normal shrinkage range, the volume decrease of the soil is equal to the water loss and the volume of the air remains constant. In the residual shrinkage range, the water loss exceeds the soil volume change, resulting in an increase in air-filled pores. In the zero-shrinkage range, there is no further decrease in the soil volume and moisture loss is due to pore drainage. The relative extent of the different shrinkage ranges varies for different soils (Parker et al., 1977). Whereas extended structural and normal shrinkage ranges may be present in highly swelling soils, only a limited normal shrinkage range may be present for low and moderately swelling soils (Tariq \& Durnford, 1993). However, the quantitative and qualitative contribution of the straw of culture left on the soil surface in aid of the soil structure and of the reduction of the soil compaction has been little studied.

The objective of this work was to value the contribution of the mulch cover of maize and oat straw, applied in the soil surface at different quantities and of the soil textural porosity at the change of the soil structural porosity.

\section{Method}

\subsection{Location, Soil Classification and Experimental Design}

The experiment was carried out from August to November 2005 on an Oxisol, FAO/UNESCO classification (1988), with clay texture, located at the Experiment Farm of Agricultural Engineering from the State University of Western Paraná (UNIOESTE, in Portuguese) Cascavel, Paraná, Brazil (245ㄴ S; 5331' W). The average soil texture in top $20 \mathrm{~cm}$ was 126,195 and $679 \mathrm{~g} \mathrm{~kg}^{-1}$ of sand, silt and clay respectively. The mean annual air temperature, precipitation and air relative moisture were $21{ }^{\circ} \mathrm{C}, 1940 \mathrm{~mm}, 75 \%$, respectively. Surface slope were $<0.5 \%$ at the field site, and thus soil erosion was negligible.

Soils sampling disturbed were collected before experiment installation, for characterization of the physicals, textural and organics properties of the soil.

It was used four applications with treatments of maize straw (Zea mays L) and oat straw (Avena sativa) were arranged in four randomized complete block design with four replicates and $1.5 \times 2 \mathrm{~m}$ (width $\times$ length) plots, separated by wooden planks (Figure 1). Three blocks have application of the oat straw and maize in ratios of 20 , 30 and $40 \mathrm{t} \mathrm{ha}^{-1}$, respectively. The witness was formed by the 4th block used without straw. After 125 days, samples disturbed were collected in the $0-5 \mathrm{~cm}, 5-10 \mathrm{~cm}$ and $10-20 \mathrm{~cm}$ depth, for determination of the textural density $\left(\rho_{t}\right)$ and organic carbon $(\mathrm{OC})$. On the same depth, samples undisturbed were collected, for determination of the gravimetric water content $(\mathrm{w})$ and soil bulk density $\left(\rho_{\mathrm{s}}\right)$, using soil cores ring $(70 \mathrm{~mm}$ in diameter, $24 \mathrm{~mm}$ in higher). 


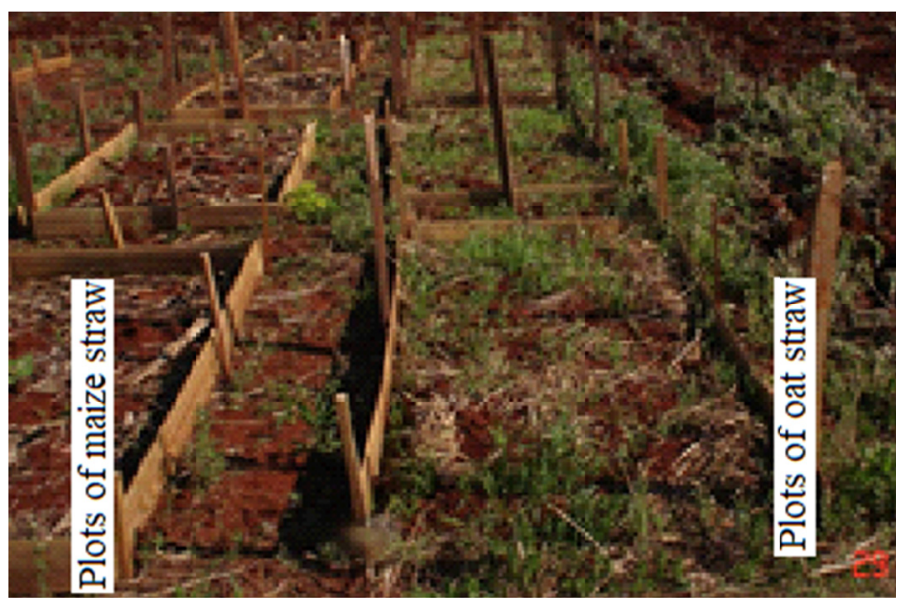

Figure 1. Part of the experimental plots with residues of maize and oat straw showing soil behaviour after 125 days

\subsection{Organic Matter}

The determination of soil organic carbon is based on the Walkley-Black chromic acid wet oxidation method as described by Bartlett et al. (1994). The analyses were determined at the laboratory of Soil of the Cooperative of Economical and Technological Development (COODETEC - Cooperativa de Desenvolvimento Econômico e Tecnológico, Paraná-Brazil, in Portuguese). Aggregates sizes distribution, soil bulk density, particles density and textural density were determined at the laboratory of the Agricultural Engineering course of the University of the West Parana State (UNIOESTE, in Portuguese) Cascavel, Paraná, Brazil.

\subsection{Soil Water Content}

Soil moisture was expressed as the water ratio, which takes into account the change in particle density due to the change in carbon content by application of the straw oat:

$$
v_{w}=\left(\rho_{s} / \rho_{w}\right) w
$$

where, $v_{w}$ is the water ratio, $\rho_{\mathrm{s}}$ is particle density $\rho_{\mathrm{w}}$ is the water density, and $\mathrm{w}$ is the gravimetric water content.

Soils samples were dried in the laboratory and then sieved to obtain aggregates with diameter 2-3.35 mm to measure the soil textural porosity as proposed by Monnier et al. (1973).

\subsection{Soil Textural and Structural Porosity}

Soil porosity was determined according to Monnier et al. (1973) as a function of pore origin. Soil porosity can be thought of as the sum of (i) macropores (structural pores) that result from tillage, traffic, weather and biological activity, and (ii) micropores (textural pores) that result from the arrangement of soil elementary particles. Structural pores are subjected to short-term variations such as compaction by wheeling, whereas compaction does not affect the textural porosity (Richard et al., 2001; Pereira et al., 2007).

It can be written:

$$
e=e_{t}+e_{s}
$$

where, $e$ is the total void ratio, $e_{\mathrm{t}}$ is the textural void ratio, and $e_{\mathrm{s}}$ is the structural void ratio.

The total void ratio can be calculated by:

$$
e=\rho_{p} / \rho_{s}-1
$$

where, $\rho_{p}$ is the soil particle density and $\rho_{s}$ is the soil bulk density. Particle density was determined by pycnometry (four replicates per soil). The textural void ratio was measured as a function of soil moisture on the aggregate fraction 2-3.35 mm using the kerosene method (Monnier et al., 1973).

Therefore, we first calculated the total void ratio using Equation (3), and then calculated the structural void ratio using Equation (2).

Shrinkage characteristic curve of the textural volume change as function of water ratio (volume of water per unit volume of solids) were obtained and estimated the ranges structural, normal, residual and and zero-shrinkage 
according to Tariq and Durnford (1993). We determine linear regression equation by using the "least squares" method at range of water ratio.

An analysis of variance was realized utilising SISVAR 5.0 (Ferreira, 2003). Comparison of means was effectuate using orthogonal contrasts, comparing soil bulk density, structural void ratio and organic carbon as function (maize straw and oat vs depth). Differences were considered statistically significant at $\mathrm{P}<0.05$.

\section{Results and Discussion}

\subsection{Soil Bulk Density}

Soil density decreased with the increase of straw cover in the soil (both oats and maize) in the superficial layer of 0 to $5 \mathrm{~cm}$ (Figure 2). Oat straw residues showed the same behavior in the depth of $5-10 \mathrm{~cm}$, but in smaller proportions. However, in the depth of $10-20 \mathrm{~cm}$, the reduction of soil density was not significant. With the increase of the maize straw in the soil, another behavior of the reduction of the soil density in the depths of 5-10 and $10-20 \mathrm{~cm}$ is verified. Oat straw showed greater effect than maize straw in reducing soil density at depths of 0 to $5 \mathrm{~cm}$. The impact of increased straw quantity on reducing soil density at depths of 5 to 10 and 10 to $20 \mathrm{~cm}$ may be influenced in part by the rate of decomposition of the straw, the time of decomposition, and the carrying of the decomposed particles on the formation of soil structure. At these depths, the application rate of maize mulch in the soil showed that values higher than 30 tha $^{-1}$ had little effect on the decrease of soil density. On the other hand, these values had important effects on the surface layer of 0 to $5 \mathrm{~cm}$, although it indicated that the increased mulch cover did not reduce soil density linearly with increasing soil depth. Soil structure and organic carbon relationships following 10 years of wheat straw management in no-till, were studied by Blanco-Canqui and Lal (2007). The results revealed that changes in soil properties due to straw mulching were mostly confined to the upper $5 \mathrm{~cm}$ of the soil. Within the upper $0-5-\mathrm{cm}$ soil depth, mulching decreased bulk density $\left(\rho_{\mathrm{b}}\right)$ by $40-50 \%$, as compared to unmulched soil.
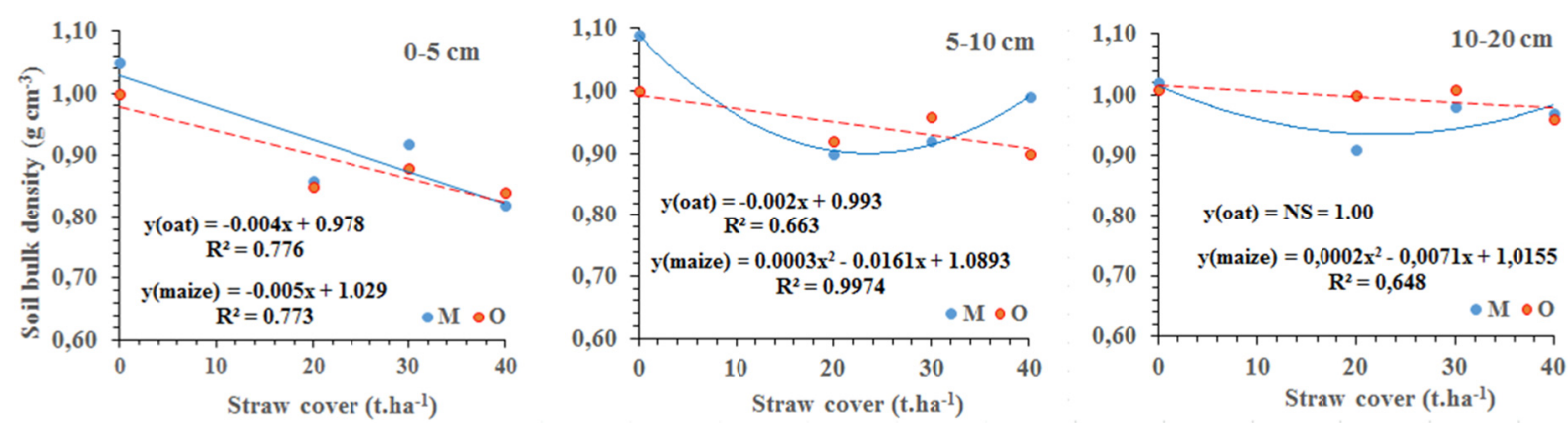

Figure 2. Soil density on the depth of $0-5,5-10$ and $10-20 \mathrm{~cm}$ as a function of the coverage mulching of maize straw (M) and of oats straw (O)

The results of our study, in short time, showed within this depth $(0-5 \mathrm{~cm})$ the decrease in soil density of $8.2 \%$, $12.3 \%$ and $16.4 \%$, respectively, with 20,30 and 40 t.ha $^{-1}$ oat straw cover, and $9.7 \%, 14.6 \%$ and $19.4 \%$ respectively, with 20,30 and 40 t.ha $^{-1}$ with maize straw cover. It can be evidenced that the maize straw favors more the reduction of the density of the soil than the oat straw. This favoring can be attributed to the rate of decomposition of the material as well as the $\mathrm{C} / \mathrm{N}$ ratio, maintaining the soil surface more protected (covered for longer), indicating the importance of the quality of the cover material on the soil surface. Straw left on the soil surface decomposes slowly and replenishes the soil with cementing organic agents continuously unlike the residues turned under (Borresen, 1999). This corroborates the better effect of maize straw than of oat straw on soil density in the surface layer in our results, since, because of its structural characteristics, corn straw provides slower decomposition than oat straw.

\subsection{Textural Voids Ratio}

For a range of water ratio lower than 0.68 , there is no difference between the textural voids ratio at the three depths (Figure 3). For water ratio higher than 0.68 , the textural void ratio is lower, for the aggregates sampled in the depth layer from 5 to $10 \mathrm{~cm}$, relative to the other depths. For this water content range, a higher textural voids ratio is obtained for the aggregates sampled in the depth layer from 0 to $5 \mathrm{~cm}$, which corresponds to greater 
microporosity. These results can have as origin the presence of greater structural porosity by the modification of the porous textural volume connected to soil compaction.

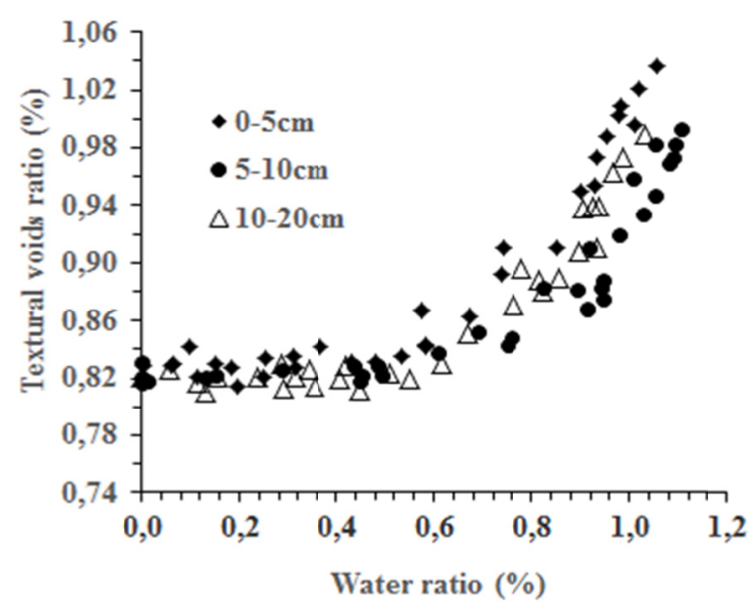

Figure 3. Textural void ratio curves from aggregates of 2-3.35 $\mathrm{mm}$ for soil layers from depths of $0-5,5-10$ and $10-20 \mathrm{~cm}$ as a function of the water ratio

The curves of textural voids ratio potential (Figure 4) are composed of a phase of retreat of water normal-aggregate saturation (sa), residual-fragile aggregates (fr) and zero-dry aggregates (strong-st), and they were separated by a critical water ratio, the air-entry point and the limit of retreat of water as defined by Gonzalez (1991), Tariq and Durnford, (1993), Sillon (1999). The residual state condition represents the location along the soil-water characteristic curve and is of interest to agricultural and environmental engineers and soil scientists. In agricultural soils, soil support capacity can be predicted, avoiding or reducing the possibility of soil compaction, a phenomenon very damaging to the agricultural production system and to the environment, since in this state condition, the soil aggregates resistance becomes stronger than the external loads applied to the soil, for example, the loads of tractors and agricultural machinery. Residual water content specifies the maximum amount of water in a soil that will not contribute to liquid flow because there is a blockage in flow paths or a strong adsorption onto the solid phase (Luckner et al., 1989). Vanapalli et al. (1998) have shown that shear strength can be predicted with a reasonable degree of accuracy using soil-water characteristic curves that have been determined without considering the influence of the stress state of soil for a net normal stress variation of 25 to $200 \mathrm{kPa}$.

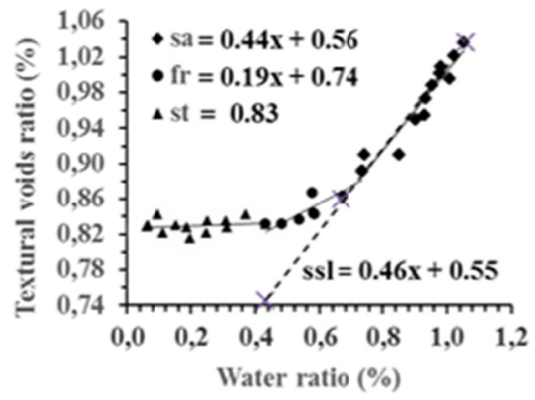

(a)

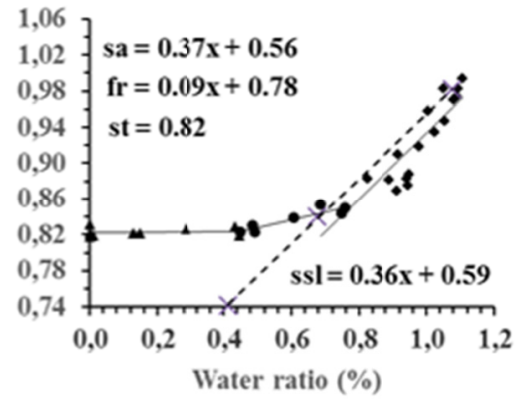

(b)

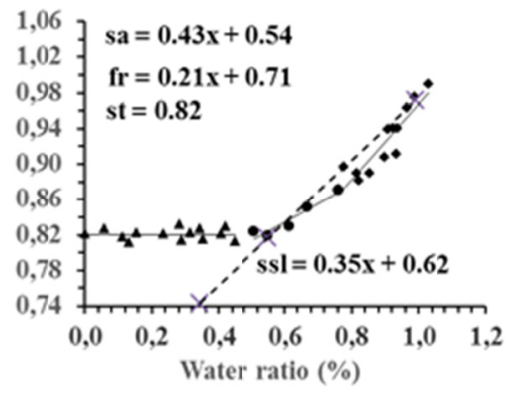

(c)

Figure 4. Textural porosity from aggregates of 2-3.35 mm on dry (strong-zero to residual state condition), fragile and saturated state characterized by the change of the air-entry point and retreat water limit, for soil layers on depths (a) $0-5$, (b) $5-10$ and (c) $10-20 \mathrm{~cm}$ as a function of the water ratio

Note. ssl-Soil saturation line. 
The textural pore space results from the organization of elementary soil particles. It is mainly affected by the soil water content and by the nature and proportions of clay, organic matter, and $\mathrm{Fe}$ and $\mathrm{Al}$ oxides. Similarly, mechanical strength of 2-3 mm aggregates only depends on the packing and cementing of the elementary particles (Barral et al., 1998).

The textural voids ratio curves for the depth of $0-5 \mathrm{~cm}$ (Figure 3a) indicate air-entry point and water-entry on the water ratio, respectively, of 0.7 and 0.5 . At the depth of $5-10 \mathrm{~cm}$, the textural air-entry point and water-entry occur in the water ratio, respectively, of 0.8 and 0.4 ; while at the depth of 10-20 they occur respectively at 0.8 and 0.5 (Figures $4 \mathrm{~b}$ and $4 \mathrm{c}$ ). Considering the soil characteristics, still without incorporation of straw, both maize and oats, in this condition, there is no protection of the organic matter within the soil in the structure of the aggregates. For the water ratio above the air-entry point, it can be assumed that the probability of water films isolating retained air volumes increases with the water content (Gonzalez, 1991). These volumes of air would be at the origin of the residual volume of structural voids along the textural saturation line or of aggregates (sa). On the other hand, for the water ratio below the air-entry point, since the aggregates are no longer saturated (fragile aggregates line-fr), these films can no longer form, causing the air to escape during compression and a zero void structural ratio is achieved.

\subsection{Soil Organic Matter}

The regression analysis showed a significant increase of the soil organic matter formed of oat straw with the increase of the application rate in all the depths of the soil. Significant $(p<0.005)$ increase of organic matter was also observed with formation of application rates of maize straw only at depths of 0 to 5 and 5 to $10 \mathrm{~cm}$ (Figure 5). The data also show that organic matter increase, produced with oat straw decreased linearly on depths of 0 to 5 and 5 to $10 \mathrm{~cm}$, while in the depth of 10 to $20 \mathrm{~cm}$, the organic matter increased with the square of the application rate of straw. Oat straw provided an increase of organic matter in the soil surface layer $(0$ to $5 \mathrm{~cm})$ with respect to the 5 to $10 \mathrm{~cm}$ layer, of $7.2 \%, 8.6 \%$ and $9.9 \%$ respectively for the covers 20,30 and $40 \mathrm{t} \mathrm{ha}^{-1}$. Regression analysis also revealed that organic matter increased significantly with increasing application rate of maize straw at depths of 0 to 5 and 5 to $10 \mathrm{~cm}$. There was no significant difference in soil depth of 10 to $20 \mathrm{~cm}$. The increase of organic matter produced by the cover of maize straw in relation to the initial value contained in the soil was of $2.2 \%, 14.7 \%$ and $35 \%$, respectively, with application rates of 20,30 and $40 \mathrm{t}$ ha, in the topsoil ( 0 to $5 \mathrm{~cm}$, organic matter initial $=47.02 \mathrm{~g} \mathrm{dm}^{-3}$ ) and $5.1 \%, 7.7 \%$ and $10.3 \%$ in the depth layer of 5 to $10 \mathrm{~cm}$ (organic matter initial $=43.9 \mathrm{~g} \mathrm{dm}^{-3}$ ) Figure 5. Blanco-Canqui and Lal (2007) found for their study SOC amount was $16.0 \mathrm{Mg} \mathrm{ha}^{-1}$ under no straw, $25.3 \mathrm{Mg} \mathrm{ha}^{-1}$ under $8 \mathrm{Mg} \mathrm{ha}^{-1}$ straw, and $33.5 \mathrm{Mg} \mathrm{ha}^{-1}$ under $16 \mathrm{Mg} \mathrm{ha}^{-1}$ straw in the 0 to $10-\mathrm{cm}$ depth. Below $10 \mathrm{~cm}$, differences in $\mathrm{SOC}$ between mulched and unmulched soil were not significant. Research conducted by Pereira et al. (2018) on four cropping systems show tendency of better distribution of organic carbon in the layer 0 to $10 \mathrm{~cm}$ in cultivation systems in the short term option (no-tillage four years) . Results also reveal that organic matter tends to decrease strongly in the 10 to $20 \mathrm{~cm}$ layer over time in the no-tillage system.

Our study shows that for all conditions: application rate and distribution in the layers of soil depth, the cover with oat straw produced more organic matter and presented a positive effect faster on the structural properties of the soil than the coverage with maize straw.

Research conducted by Mupangwa et al (2013) showed that Soil organic carbon increased with time in all tillage systems and more SOC gained in planting basins. Soil bulk density decreased with time in all tillage systems irrespective of mulch quantity applied. Results of this research show that the soil density decreased in all the layers with both the mulch of the oat straw and with the mulch of maize straw (Figure 2) in both with the mulch quantity applied, except with the coverage of oat straw which showed no significant difference in the depth layer of 10 to $20 \mathrm{~cm}$. 

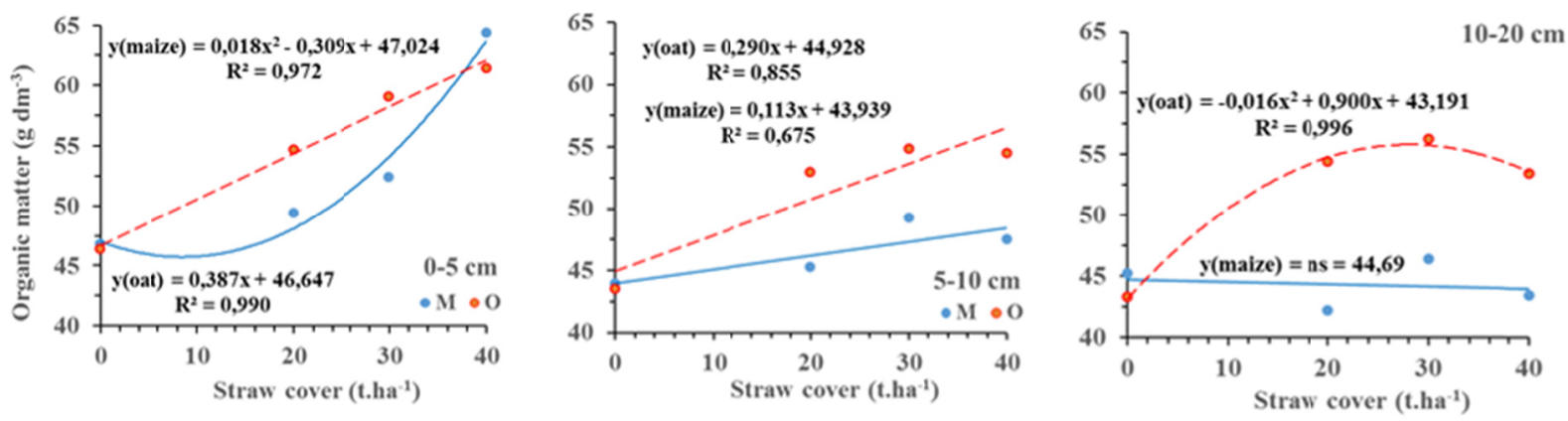

Figure 5. Soil organic matter for soil layers on depths $0-5,5-10$ and $10-20 \mathrm{~cm}$ as a function of application of maize straw and oat straw on the soil cover

Note. ns-not significant.

\subsection{Structural void ratio}

According to Stengel (1990), for many low volume materials, variations in the volume of the soil layer with their water content are not detectable. For this hypothesis, assuming the total porosity independent of the water content, or calculating its variations from those of the aggregates under the hypothesis of distribution of isotropic contraction, one can calculate the variation of the structural porosity as a function of the humidity.

From the results of Figure 6, it can be clearly seen that both maize straw as oat straw in the soil cover had a greater effect on the structural void ratio, on the surface layer of the soil $(0$ to $5 \mathrm{~cm})$ than on the depth layers 5 to $10 \mathrm{~cm}$ and 10 to $20 \mathrm{~cm}$. In the uncovered soil condition, it can be verified that the area covered with oat straw revealed a better initial structural state than the area covered with maize straw (structural void index greater $18.34 \%$ and $36.61 \%$, respectively, at depths 0 to $5 \mathrm{~cm}$ and 5 to $10 \mathrm{~cm}$ ).

There is practically no improvement in the structural void ratio with the increase of maize straw in the depth layer of 10 to $20 \mathrm{~cm}$. However, it is verified that there was an increase in the structural porosity (even low) in this depth with the increase of the oat straw. Following Borressen (1999) reasoning, our hypothesis is that oat straw by its own properties produced the faster decomposition that the maize straw, in addition to forming smaller particles in the short time. As shown by Figure 5, this soil had the highest initial structural void ratio, at depths of 0 to 5 and 5 to $10 \mathrm{~cm}$, compared to the one where the maize straw experiment was installed. Thus, the transport of the decomposed oat straw particles may have occurred for the depth layer of 10 to $20 \mathrm{~cm}$ with ease, producing structural void index growth with the increase of the applied oat straw. Aggregates with lower wettability such as those from mulched soil were more water-stable and less dispersed than those with higher wettability. It is believed that our study follows the hypothesis of hydrophobicity according to Chenu et al. (2000) that the hydrophobicity of oat straw may be due to the presence of humic acids, aliphatic substances, and organic polymers. Borresen (1999) stated that straw residues released organic acids, which serve as strong binding agents of soil particles into aggregates. It is also evidenced that growth of the soil structural voids ratio correlated in this study to two physical properties as: reduction of the textural voids ratio, as perceived in Figures 3 and 4c, as well as the decrease of soil bulk density (Figure 2) probably due to the effect of the low density of the organic compound produced by oat straw. The lower bulk density and higher aggregate density under mulched soil imply increased porosity and improved soil structure by mulching supported by the high rate of organic carbon concentration (Figure 5). Our results reflect those obtained in the study of Blanco-Canqui and Lal (2007) which reported that both SOC concentration and aggregate structure were highly correlated with soil physical properties, indicating that were strong determinant of soil structural properties. 

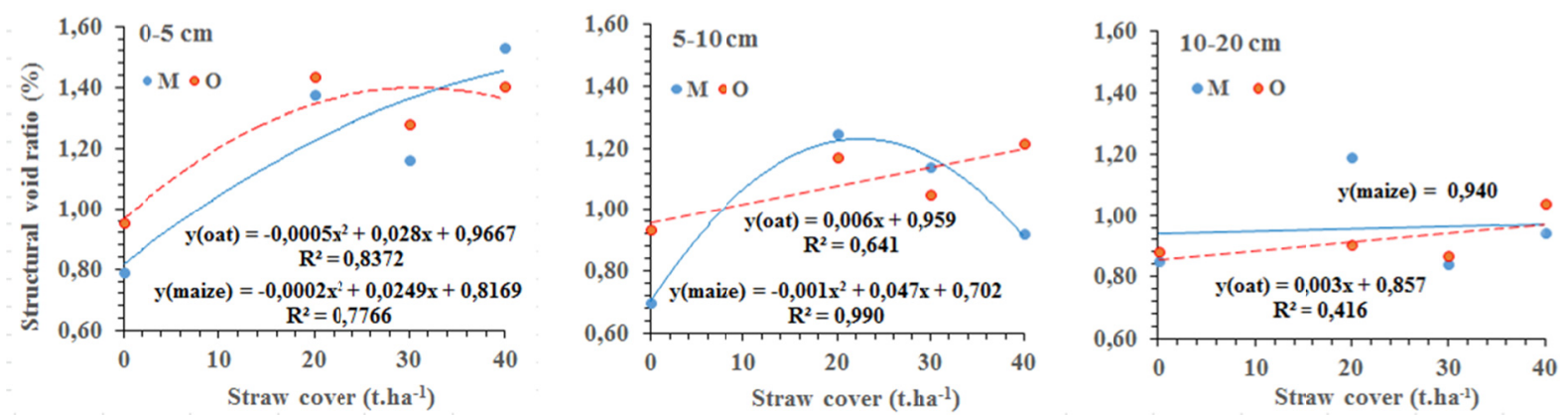

Figure 6. Soil structural void ratio for soil layers on depths $0-5,5-10$ and 10-20 cm as function of application of mulching of maize straw and mulching fo oat straw on the soil cover

\section{Conclusion}

The mulch of maize straw and oat straw significantly reduced soil density at all depths with increasing the amount of straw, compared to uncovered soil, except with the coverage of oat straw that reduced only at the depths of 0 to 5 and 5 to $10 \mathrm{~cm}$. The lowest density was recorded in the soil surface layer with all the mulchs. For all conditions: application rates, and distribution in the layers of soil depth, the cover with oat straw produced more organic matter and presented a positive effect faster on the soil structural voids ratio than the coverage with maize straw. The lower bulk density and higher aggregate density under mulched soil imply increased porosity and improved soil structure by mulching supported by the high rate of organic carbon concentration, reflecting the residue mulch influence on soil structural properties.

\section{References}

Annooussamy, M. P. (1999). Evolution Du comportement mécanique des pailles de blé après la récolte conséquences sur la gestion de la paille (p. 115, Thèse Docteur Ingénierie, Institut National Agronomique-Paris-Grignon, Paris).

Aragón, A., García, M. G., Filgueira, R. R., \& Pachepsky, Y. A. (2000). Maximum compactibility of Argentine soils from the Proctor test: The relationship with organic carbon and water content. Soil and Tillage Research, 56, 197-204. https://doi.org/10.1016/S0167-1987(00)00144-6

Barral, M. T., Arias, M., \& Guérif, J. (1998). Effects of iron and organic matter on the porosity and structural stability of soil aggregates. Soil \& Tillage Research, 46, 261-272. https://doi.org/10.1016/S0167-1987(98) 00092-0

Barzegar, A. R., Asoodar, M. A., \& Ansari, M. (2000). Effectiveness of sugarcane residue incorporation at different water contents and the Proctor compaction loads in reducing soil compactibility. Soil and Tillage Research, 57, 167-172. https://doi.org/10.1016/S0167-1987(00)00158-6

Bartlett, G. N., Craze, B., Stone, M. J., \& Crouch, R. (1994) Guidelines for Analytical Laboratory Safety. Department of Conservation \& Land Management, Sydney.

Blanco-Canqui, H., \& Lal, R. (2007). Soil structure and organic carbon relationships following 10 years of wheat straw management in no-till. Soil and Tillage Research, 95, 240-254. https://doi.org/10.1016/j.still.2007. 01.004

Boiffin, J., \& Monnier, G. (1994). Suppression Du labour et érosion hidrique dans le contexte agricole français: Bilan et possibilitéd'application des référence disponibles. In Simplification du travail du sol, Edition Les colloques de l'INRA, 65, 85-103.

Borresen, T. (1999). The effect of straw management and reduced tillage on soil properties and crop yields of spring-sown cereals on two loam soils in Norway. Soil and Tillage Research, 51, 91-102. https://doi.org/ 10.1016/S0167-1987(99)00030-6

Brussaard, L., \& van Faassen, H. G. C. (1994). Effects of compaction on soil Biota and soil biological processes. In B. D. Soane, \& C. van Ouwerkerk (Eds.), Soil Compaction and Crop Production. Developments in Agricultural Engineering (pp. 1-21). Elsevier, Amsterdam. https://doi.org/10.1016/B978-0-444-88286-8. 50018-0 
Chenu, C., Bissonnais, Y., \& Le Arrouays, D. (2000). Organic matter influence on clay wettability and soil aggregate stability. Soil Science Society of American Journal, 64, 1479-1486.

Eynard, A., Schumacher, T. E., Lindstrom, M. J., Malo, D. D., \& Kohl, R. A. (2006). Effects of aggregate structure and organic C on wettability of Ustolls. Soil and Tillage Research, 88, 205-216.

FAO. (1988). FAO/UNESCO soil map of the world, revised legend (p. 138). World Resources Report 60. FAO, Rome. Reprinted as Technical Paper 20, ISRIC, Wageningen.

Ferreira, D. F. (2003). Sistema SISVAR para análises estatísticas: Manual de Orientação (p. 37). Lavras: Departamento de Ciências Exatas, Universidade Federal de Lavras.

Fox, D. M., Bryan, R. B., \& Fox, C. A. (2004). Changes in pore characteristics with depth for structural crusts. Geoderma, 120, 109-120. https://doi.org/10.1016/j.geoderma.2003.08.010

Gonzalez, F. L. (1991). Morphologie, proprietes physiques et conditions de formation des elements structuraux de la couche labouree: Contribution à interprétation du profil cultural (p. 179, Thèse (Docteur Ingénierie), Institut National Agronomique, Paris-Grignon, Paris).

Guérif, J. (1979). Mechanical properties of straw: The effect on soil. In E. Grossbard (Ed.), Straw Decay and its Effect on Disposal and Utilization (pp. 73-81). Wiley, Chichester, UK.

Gupta, S. C., Schneider, E. C., Larson, W. E., \& Hadas, A. (1987). Influence of corn residue on compression and compaction behaviour of soils. Soil Science Society of America Journal, 51, 207-212. https://doi.org/ 10.2136/sssaj1987.03615995005100010043x

Horn, R. (1990). Aggregate characterization as compared to soil bulk properties. Soil and Tillage Research, 17, 265-289. https://doi.org/10.1016/0167-1987(90)90041-B

Lipiec, J., \& Hatano, R. (2003). Quantification of compaction effects on soil physical properties and crop growth. Geoderma, 116, 107-136. https://doi.org/10.1016/S0016-7061(03)00097-1

Lipiec, J., Walczak, R., Witkowska-Walczak, B., Nosalewicz, A., Slowinska-Jurkiewicz, A., \& Slawinski, C. (2007) The effect of aggregate size on water retention and pore structure of two silt loam soils of different genesis. Soil and Tillage Research, 97, 239-246. https://doi.org/10.1016/j.still.2007.10.001

Luckner, L., van Genuchten, M. T., \& Neilsen, D. R. (1989). A consistent set of parameteric models for the flow of water and air as immiscible fluids in the subsurface. Water Resource Research, 25, 2187-2189. https://doi.org/10.1029/WR025i010p02187

McGregor, K. C., Bengston, R. L., \& Mutchler, C. K. (1990). Surface and incorporated wheat straw effects on interrill runoff and soil erosion. Transaction of the American Society of Agricultural Engineers, 33(2), 469-474. https://doi.org/10.13031/2013.31352

Monnier, G., Stengel, P., \& Fies, J. C. (1973). Une method de mesure de la densité apparente de petits agglomerats terreux: Application à l'analyse des systems de porosité du sol. Annales gronomiques, 24, 533-545.

Mupangwa, W, Twomlow, S., \& Walker, S. (2013). Cumulative effects of reduced tillage and mulching on soil properties under semi-arid conditions. Journal of Arid Environments, 91, 45-52. https://doi.org/10.1016/j. jaridenv.2012.11.007

Parker, J. C., Aamos, D. F., \& Kaster, D. L. (1977). An evaluation of several methods of estimating soil volume change. Soil Science Society of America Journal, 41, 1059-1064. https://doi.org/10.2136/sssaj1977.0361599 $5004100060008 \mathrm{x}$

Pereira, J. O., Défossez, P., \& Richard, G. (2007). Soil susceptibility to compaction by wheeling as a function of some properties of a silty soil as affected by the tillage system. European Journal of Soil Science, 58, 34-44. https://doi.org/10.1111/j.1365-2389.2006.00798.x

Pereira, J. O., de Melo, D., Richard, G., Defossez, P., Silva, S. L., de Oliveira, F. A., ... Garcia, A. R. G. (2018). Yield of soybean crop in function of soil compaction affected by tillage system on Oxisol of subtropical region. Australian Journal of Crop Science, 12(2), 227-234.

Richard, G., \& Boiffin, J. (1990). Effet de l'état structural du lit de semence sur la germination et la levée des cultures. In La structure du sol et son évolution, Edition Les colloques de l'INRA, 53, 111-136. 
Richard, G., Cousin, I., Sillon, J. F., Bruand, A., \& Guèrif, J. (2001). Effect of compaction on soil porosity: Consequences on hydraulic properties. European Journal of Soil Science, 52, 49-58. https://doi.org/ 10.1046/j.1365-2389.2001.00357.x

Sharma, P., Singh, G., \& Singh, R. P. (2011) Cnservation tillage, optimal water and organic nutrient supply enhance soil microbial activities during wheat (Triticum aestivum L.) cultivation. Brazilian Journal of Microbiology, 42, 531-542. https://doi.org/10.1590/S1517-83822011000200018

Shinners, K. J., Nelson, W. S., \& Wang, R. (1994). Effects of residue-free band width on soil temperature and water content. Transactions of the American Society of Agricultural Engineers, 37(1), 39-49.

Sillon, J. F. (1999). Étude expérimentale et modélisation des effets de la structure de la couche labourée sur le régime hydrique du sol nu en phase de dessèchement: Application à la prévision des jours disponibles ( $\mathrm{p}$. 223, Thèse (Docteur Ingénierie), Institut National Agronomique, Paris-Grignon, Paris).

Stengel, P. (1990). Caractérisation de l'état structural du sol: Objectifs et méthodes. In J. Boiffin (Ed.), La Structure Du Sol et Son Evolution: Conséquences Agronomiques, Maîtrise Par L'agriculteur, Les Colloques de l'INRA.

Tariq, A. R., \& Durnford, D. S. (1993). Analytical volume model for swelling clay soils. Soil Science Society of America Journal, 57(5), 1183-1187. https://doi.org/10.2136/sssaj1993.03615995005700050003x

Vanapalli, S. K., Sillers, W. S., \& Fredlund, M. D. (1998). The Meaning and relevance of residual state to unsaturated soils. 51st Canadian Geotechnical Conference, Edmonton, Alberta, October 4-7, 1998.

Zhang, H., Hartge, K. H., \& Ringe, H. (1997). Effectiveness of organic matter incorporation in reducing soil compactibility. Soil Science Society of America Journal, 61, 239-245. https://doi.org/10.2136/sssaj1997. $03615995006100010033 x$

\section{Copyrights}

Copyright for this article is retained by the author(s), with first publication rights granted to the journal.

This is an open-access article distributed under the terms and conditions of the Creative Commons Attribution license (http://creativecommons.org/licenses/by/4.0/). 